\title{
Adolescentes y VIH/Sida
}

\author{
Margarita Martínez
}

Una realidad país: Adolescencia y VIH/Sida

V

IH/Sida es una de las epidemias de mayor preocupación en todo el mundo regiones como África y Asia han sido gravemente afectadas. En algunos países de regiones como lo es América Latina un aparente bajo crecimiento influye en la ineficiente respuesta para enfrentar la epidemia. Es conocido que el VIH/Sida no tiene discrimen social, económico, edad, género, etc. Sin embargo, hay grupos poblacionales en los que la epidemia crece con mayor rapidez, entre estas poblaciones están los/as adolescentes.

La UNICEF calcula que en la región de América Latina, cada hora, siete personas resultan infectadas con el VIH; la mitad de ellos son niños, niñas, adolescentes y jóvenes entre los 10 y 24 años de edad.

Mucho/as adolescentes están infectad los/as por el virus del VIH/Sida a sus 15,16 años de edad o menos aún; una de las principales razones es que la mayoría de ellos y ellas están manejando su vida sexual desconociendo su condición de vulnerabilidad. Los/as mayormente afectad los/as por la epidemia son adolescentes que tienen menos oportunidades a una información certera y programas sostenidos en educación para la prevención del VIH/Sida. Según informe de las Naciones Unidas a diciembre de

\footnotetext{
"Coordinadora del programa de educación y prevención MAP Internacional, oficina Ecuador.
} 
2002, 6000 adolescentes se infectan cada día a nivel mundial ${ }^{1}$.

Los/as adolescentes viven cambios fisiológicos, físicos, emocionales, afectivos, todos ellos determinantes en la necesidad de vivir experiencias en el ejercicio de su sexualidad, frente a esta demanda se encuentran con una ausencia o deficientes respuestas que permitan acompañar este proceso de cambios y no ser afectados por realidades como la del $\mathrm{VIH} /$ Sida.

El riesgo que hoy están enfrentando los/as adolescentes no solo depende de sus actitudes y comportamientos, es importante tener un enfoque más amplio de la realidad y esto nos lleva a entender que Ecuador es un país en el que su población día a día enfrenta condiciones altamente vulnerables económica, social y políticamente.

En los primeros años de la epidemia en nuestro país, el índice de casos por infección de VIH/Sida eran muy bajos, está es una de las razones para que como país hayamos descuidado el crecimiento en adolescentes y el resto de poblaciones. Sin embargo en los últimos años las cifras han alcanzado un crecimiento que llama la atención

Según datos oficiales publicados por el Programa Nacional de Sida, durante el 2004 hubieron 1006 nuevos casos, de estos el $22 \%$ corresponde a jóvenes entre los 16 y 24 años de edad.

${ }^{1}$ Informe ONUSIDA diciembre del 2003. 
NUEVOS CASOS POR VIH/SIDA Y PROVINCIA

EN ADOLESCENTES Y JÓVENES DURANTE EL AÑO 2004 - ECUADOR

\begin{tabular}{|c|c|c|c|c|c|c|c|c|}
\hline Edad & El Oro & Esmeraldas & Guayas & $\begin{array}{l}\text { Los } \\
\text { Ríos }\end{array}$ & Manabí & Pichincha & $\begin{array}{c}\text { Otras } \\
\text { provincias }\end{array}$ & Total \\
\hline $\begin{array}{c}15-19 \\
\text { años }\end{array}$ & 4 & 2 & 25 & 2 & 1 & 8 & 3 & 45 \\
\hline $\begin{array}{c}20-25 \\
\text { años }\end{array}$ & 10 & 8 & 98 & 6 & 11 & 25 & 17 & 175 \\
\hline 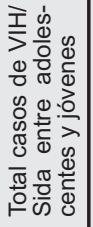 & 14 & 10 & 123 & 8 & 12 & 33 & 20 & 220 \\
\hline
\end{tabular}

Los datos nos revelan que existe una mayor concentración de la epidemia en jóvenes que están entre los 20 y 25 años de edad, la razón para esto es que por lo general los/as adolescentes que han sido infectados/as por VIH son diagnosticados/as cuando llegan a sus 24 ó 25 años.

Los datos reflejan también que la mayor concentración se da en las ciudades de mayor población, que son Guayaquil y Quito, la explicación radica en las personas acuden a los centros hospitalarios de estas ciudades en busca de mejor atención y servicios, en la convicción que teniendo mayor infraestructura serán mejor atendidas.

NUEVOS CASOS POR VIH/SIDA Y SEXO

EN ADOLESCENTES Y JÓVENES DURANTE EL AÑO 2004

\begin{tabular}{|c|c|c|c|}
\hline Edad & Hombres & Mujeres & Total \\
\hline $15-19$ & 27 & 18 & $\mathbf{4 5}$ \\
\hline $20-25$ & 107 & 68 & $\mathbf{1 7 5}$ \\
\hline Total & 134 & 86 & $\mathbf{2 2 0}$ \\
\hline
\end{tabular}


El cuadro anterior revela que la relación de hombres y mujeres jóvenes con VIH/Sida es de 2 a 1 , esta situación nos muestra que cada vez hay más mujeres jóvenes que se han infectado en su adolescencia, pues tan solo el año anterior la relación por infección de $\mathrm{VIH} /$ Sida entre hombre y mujeres era de 3 a 1.

\section{Percepción del VIH/Sida desde los adolescentes: mitos y realidades}

La mayor parte de adolescentes tienen una información básica sobre VIH/Sida, consideran que es una epidemia propia del África, de países lejanos, no perciben que es una epidemia que ya está afectando gravemente al país y que ellos y ellas están dentro de las poblaciones más afectadas.

Muchos/as de ellos y ellas ignoran cómo se transmite el virus del sida, como no se trasmite, su comportamiento en el organismo humano, etc. En un estudio realizado por Naciones Unidas en el 2003, se indica que el $50 \%$ de adolescentes tienen ideas equivocadas e incompletas sobre la transmisión del virus, esto preocupa sobre todo por que es precisamente durante la adolescencia cuando muchos de ellos/as inician su actividad sexual.

Estos datos se confirman cuando en talleres sobre educación y prevención de $\mathrm{VIH} / \mathrm{Sida}$, realizados por MAP Internacional Organismo que tiene un Programa de Educación y Prevención en VIH/Sida con población adolescente, entre noviembre del 2003 y febrero del 2005, alrededor del $30 \%$ considera que:

- El VIH/Sida es una enfermedad de gays, "prostitutas", "gente promiscua"

- Que se transmite por un mosquito

- Que se pueden infectar en una peluquería 
- Que pueden infectarse en una piscina

- Que una persona con VIH/Sida puede infectar a otra por usar la misma vajilla

- Que se pueden infectar a través del sudor o la saliva.

- Que se pueden infectar si en el cine les pican con una aguja.

- Las chicas que andan con uno y con otro son las que se pueden infectar.

- Si una sola vez no usa condón no se infectan.

- El condón es feo y no es lo mismo.

- El examen pueden realizarse al otro día o la semana siguiente de haberse infectado.

- VIH es lo mismo que Sida.

Las opiniones anteriores son algunos de los mitos e información equivocada, así también en sus opiniones hay muchas contradicciones, porque a pesar que para ellos/as el riesgo de infección es una cuestión de "grupos de riesgo", por otra hablan de situaciones ocasionales en las que todos/as incluidos ellos/as están en riesgo.

Entre mitos y realidades que tiene como información la población adolescente y el riesgo al que se enfrentan a diario en sus relaciones cotidianas, condiciones de vida, etc. Se hace urgente que desde el gobierno y la sociedad civil se emprendan programas sostenidos sobre educación para una sexualidad saludable e información, sensibilización y prevención en $\mathrm{VIH} /$ Sida con niños/as y preadolescentes.

Actitudes y comportamientos de riesgo frente al VIH/Sida en adolescentes entre 14 y 18 años

La mayor parte de los casos de transmisión del virus del VIH/Sida responden al factor de transmisión sexual, en Ecuador este factor representa más del $93 \%$ de los casos 
de VIH/Sida. En los espacios de participación que tienen los/as adolescentes y en los que se aborda el tema de su vida sexual, se confirma que actualmente muchos de ellos hombres y mujeres, de distinta clase social, entornos, religión, antes de cumplir los 18 años viven situaciones de riesgo ante enfermedades de transmisión Sexual y el VIH/Sida, como por ejemplo: tener relaciones tempranas, relaciones sexuales desprotegidas, tener relaciones son varias parejas, mantener relaciones sexuales ocasionales y con personas desconocidas.

Sin embargo, lo que interesa conocer es porqué viven estas situaciones de riesgo, que otros factores influyen para que los vivan y como los perciben en sus diferentes contextos, para los/as adolescentes los factores mayormente determinantes en sus actitudes y comportamientos de riesgo son:

\section{La presión social en el grupo}

"Un amigo me dice el otro día: tener relaciones, es lo máximo loco, es como aprender a fumar"2

"Un primo mío me llevó a la Amazonas a pegarme el primer polvo con una pelada de esas que andan por ahí, pero después me dio asco, se sentí super mal, me hubiese gustado que sea de otra forma, no solo por experimentar"3.

"Las chicas que ya han tenido relaciones sexuales nos dicen, es pleno, lo que tienes que hacer es cuidarte de un embarazo y punto, pero lo disfrutas"4.

"Entre los amigos friegan y friegan, hasta que logran, y algunos locos por no quedarse fuera del grupo

\footnotetext{
${ }^{2}$ Adolescente hombre, 16 Años, enero 1998.

${ }^{3}$ Adolescente, hombre, 18 años, enero 1998.

${ }^{4}$ Adolescente, mujer, 14 años, febrero de 1998.
} 
caen y se dejan influir por los amigos, entonces toman hasta embrutecerse, después de eso puede pasar todo, a veces no saben con quien se acostaron" .

Estas son solo algunas de las opiniones que confirman que la presión social que enfrentan a diario los chicos en sus propios grupos es un fuerte factor que influye en que actualmente vivan situaciones de riesgo como uso de alcohol, drogas, embarazo, enfermedades de transmisión sexual y VIH/Sida.

Para muchos la necesidad de sentirse reconocidos, aceptados, valorados, hace que asuman actitudes y comportamientos de riesgo, el que no lo hace es un "hijito de mamita", además hay un fuerte prejuicio en relación a la identidad sexual, el que no lo hace es homosexual.

"Lo que pasa, es que en el grupo de amigos joden y joden, dicen que fue cuando loco... entonces uno se siente mal, a veces uno se siente presionado a probarse y demostrarles a los amigos que no es ningún mariquita" 6 .

Expresiones como estas demuestran que aún entre los jóvenes los prejuicios ligados a la vida sexual como parte de un sistema cultural están fuertemente enraizados y que se han transmitido a través de las generaciones a pesar de que hoy viven expuestos a influencias de otros factores culturales.

Entre las chicas esta situación también es una realidad, porque la que no lo hace es considerada fuera de espacio. Algunas adolescentes expresan que a veces terminan haciendo lo que el grupo exige por miedo a sentirse rechazadas, a que las aparten, no les inviten otra vez a salir, y esto les hace sentirse menos. Sin embargo, la presión del grupo entre las mujeres es menor porque también están presentes mitos, prejuicios, creencias.

Hombres y mujeres en su adolescencia están pasan-

${ }^{5}$ Adolescente, hombre, 15 años, febrero 1998. 
do por una etapa de cambios, físicos afectivos, emocionales, sociales, culturales que les lleva a querer aprender experimentando lo nuevo, lo desconocido, a probar que es verdad o no lo que se dicen entre ellos "pegarse un polvo es lo máximo" no, no pasa nada si te cuidas". Las relaciones sexuales que tienen entre los/as adolescentes están ligadas a una etapa en la que están viviendo cambios físicos internos y externos, donde ellos se van siento hombres jóvenes y ellas mujeres jóvenes, una etapa además en la que empiezan a exteriorizar su sexualidad a través de la atracción física, afectiva, emocional, la seducción, el coqueteo y la conquista.

No olvidemos que dentro de estos cambios se entretejen además factores culturales, el hombre tiene que ser hombre y demostrarlo desde su adolescencia. Para los varones es muy importante probarse a sí mismo y probar a los demás su virilidad, tomando en cuenta que a pesar de los cambios de aceptación y/o respeto de la sociedad ecuatoriana frente al tema de homosexualidad, aún persisten actitudes de discrimen. Estas consideraciones hacen que los varones tengan miedo a ser identificados de homosexuales, porque sienten que serán juzgados por sus amigos, las chicas, la familia, y el resto de la sociedad.

En el caso de las mujeres está muy clara el prejuicio de que son rechazadas si alguien descubre que ya han tenido relaciones sexuales, ellas no pueden mientras que los hombres sí, por eso ellas deben cuidarse.

\section{La falta de atención de los padres}

"Yo creo que una de las razones para que muchas chicas tengan relaciones sexuales, es por la falta de orientación de sus padres, la falta de afecto, de cariño, enton- 
ces van donde su enamorado que si les da todo eso y ahí no más pasa todo"”.

"Mi papá jamás, pero jamás conversa conmigo, llega de la oficina y ni me habla, ni me pregunta como estoy en el colegio, come, y se acuesta".

La ausencia de los padres ante las situaciones que viven los/as jóvenes es otro factor de riesgo, la falta de atención, de comunicación entre padres e hijos, la controversia en la forma de actuar y comportarse desde dos generaciones diferentes y expuestas también a realidades sociales distintas, la necesidad de que hoy tengan que trabajar padre y madre para poder cubrir las demandas económicas del hogar. Son entre otros factores los que generan un distanciamiento, que hace que poco a poco el afecto, el cariño, el diálogo estén ausentes entre padres e hijas, esto hace también que los hijos/as no se sientan autoestimados por sus padres y busquen llenar su autoestima en el reconocimiento del en espacios sociales que influyen en actitudes y comportamientos que los/as exponen a riesgos ya mencionados.

\section{Medios de comunicación}

"Cuando uno llega del colegio, llega cansado y prende la televisión y empieza a ver programas en los que trabajan peladas con casi nada de ropa y se nos va metiendo ideas en la cabeza y se nos viene la excitación, además los medios lo dicen como que es lo mejor, eres más hombre si lo pruebas todo"'.

Los medios de comunicación es un importante factor de influencia en las situaciones de riesgo, muchos de ellos en lugar de orientar, motivan a que adolescentes se expon-

\footnotetext{
${ }^{7}$ Adolescente mujer, abril del 2004.

${ }^{8}$ Adolescente hombre, abril del 2004.

${ }^{9}$ Adolescente hombre noviembre del 2004.
} 
gan al uso de alcohol, vida sexual activa, en su conducción no hay ningún sentido de orientación, de sugerir prevenir los riesgos que actualmente enfrentan los chicos y las chicas...

Los estudios realizados en relación a comportamientos sexuales y riesgo frente al embarazo y/o $\mathrm{VIH} /$ Sida confirman que la realidad no ha cambiado y tampoco se ha avanzado en la sensibilización de la población adolescente en relación a la posibilidad de infectarse con VIH/Sida.

Entre diciembre del 2004 y enero del 2005 en Quito, en el Proyecto "Los y las adolescentes por una salud plena y responsable" realizó una línea de base con 800 estudiantes adolescentes, el estudio revela datos como que el $69 \%$ tuvieron su primera relación sexual entre los 11 y 15 años, el $66 \%$ indica haber usado preservativo en sus relaciones sexuales. Sobre $\mathrm{VIH} / \mathrm{Sida}$ el $94 \%$ dice conocer sobre $\mathrm{VIH} /$ Sida, el 95\% dice que se pueden infectar teniendo relaciones sexuales sin preservativo, el $31 \%$ indica que se pueden infectar por usar sanitario público y el $21 \%$ no sabe, el $29 \%$ dice entender que se pueden infectar usando la misma vajilla que antes utilizó una persona con $\mathrm{VIH} /$ Sida y el $26 \%$ no sabe ${ }^{10}$.

Cuando se profundiza con los/as adolescentes sobre sus relaciones sexuales ellos y ellas indican que han usado alguna vez o varias veces un preservativo, pero también confirman que no han usado en todas sus relaciones, más aún no lo han usado en la mayoría de las veces. Esta falta de sensibilización frente al riesgo que se expongan es lo que preocupa sobre sus actitudes y comportamientos y la información que manejan sobre VIH/Sida.

Los datos nos revelan que cada vez el VIH/Sida sigue avanzando de forma alarmante y no se están toman-

${ }^{10}$ PROYECTO PILOTO LÍNEA DE BASE, Los y las adolescentes por una salud plena y responsable, marzo del 2005. 
do medidas urgentes y efectivas para reducir el crecimiento entre las generaciones más jóvenes que son en muchos de los casos el motor de una sociedad aletargada frente a realidades sociales que nos está dividiendo como país.

\section{Condiciones estructurales de vulnerabilidad}

En el Ecuador así como otros países en desarrollo, debemos entender el impacto de la epidemia en un contexto más allá de la salud pública. Pues además de la salud comprendida desde el enfoque biomédico, la epidemia en nuestro país está enfrentada a realidades preocupantes en otros aspectos: emocional, social, político y económico; expresadas en situaciones tangibles de: pobreza, hambre; condiciones de salud y servicios médicos inadecuados; estigmatización y discriminación de poblaciones que viven en condiciones de vulnerabilidad; políticas públicas que no ofrecen garantías suficientes para hacer efectivos el respeto por los Derechos Humanos.

La población ecuatoriana vive día a día condiciones de alta vulnerabilidad frente al VIH-Sida, los factores mencionados han dotado de una fuerza particular a las devastadoras consecuencias de la epidemia. La ausencia de programas efectivos en la prevención, así como el deficiente control, y aun pocos esfuerzos de atención eficiente a las personas que viven con el VIH-Sida, son solo un reflejo de que lo que ocurrirá en 5 años más, de no hacer esfuerzos efectivos en el ámbito de la prevención y asistencia de la epidemia.

El VIH-Sida es una epidemia de la pobreza, pues esta población es la que se encuentra ahora en mayor riesgo de infección por VIH. A finales del 2004, según datos proporcionados por el Programa Nacional de Sida, en el Ecuador las poblaciones mayormente afectadas según su ocupación son de condiciones social y económicamente 
más afectadas esto se refleja en el $79 \%$ del total de los 1006 nuevos casos reportados oficialmente por el Programa Nacional de SIDA: Obreros y obreras el 19\%, comerciantes informales $10 \%$, desocupados y desocupadas $22 \%$ y quehaceres domésticos el $34 \%{ }^{11}$.

Estos datos nos llevan a pensar en que se está afectando el ingreso per cápita del país porque, implica menos días de trabajo, menores oportunidades de obtener empleos mejor remunerados y tiempos de vida más cortos.

A esta situación se suman, los despidos intempestivos que viven las personas que sufren con el VIH-Sida, cuando en su lugar de trabajo se enteran que tienen un diagnóstico VIH positivo. Muchos de ellos/as son padres o madres de familia, quienes tienen bajo su responsabilidad la sostenibilidad económica de su familia. Al ser despedidos se cierran más aún sus posibilidades de conseguir un nuevo trabajo, por otro lado los requerimientos de muchas empresas y otros lugares de empleo, que exigen la prueba de anticuerpos al $\mathrm{VIH}$; el examen de Elisa (examen básico para detectar el virus del VIH-Sida) como condición previa a realizar contrataciones.

Además de poder entender la realidad $\mathrm{VIH} /$ Sida con un enfoque de desarrollo social en términos de la población actualmente afectada, debe tenerse en cuenta que la situación de pobreza empuja cada año a migrar interna y externamente, este factor determina otro problema que es la desestructuración familiar, muchos padres dejan a sus hijos/as solos/as sin el apoyo, afecto, y acompañamiento que sus hijos/as adolescentes requieren en una etapa de sus vidas en las que requieren un referente de orientación, de apoyo, de comprensión; como consecuencia de ello sus hijos/as buscan cubrir sus necesidades en entornos poco saludables física, emocional, afectiva y espiritualmente.

\footnotetext{
${ }^{11}$ Programa Nacional de Sida, Ecuador, enero 2005.
} 
Padres de familia que han migrado fuera del país lo hicieron con el objetivo de mejorar su situación económica y muchos de ellos compensan su ausencia enviando dinero a sus hijos/as, muchos de ellos/as adolescentes que al verse son dinero en sus manos lo usan en actividades de diversión que están vinculadas con el uso de alcohol, droga, y estos son factores canalizadores a otras situaciones como violencia, relaciones sexuales desprotegidas, entre otros riesgos.

"Muchos adolescentes dejan de estudiar cuando empiezan a manejar dinero, ellos/as sienten que ya no necesitan esforzarse más si tienen quién les provea recursos para sus satisfacer sus gustos (celular, diversión, licor, experiencias sexuales, etc.).

"Mi amigo dice que sus papás ya tienen plata y le mandan, por eso él ya no va al colegio, anda con otros manes, el otro día estaba super borracho, tiene una pelada que también sabe andar borracha con él "12.

La mejor herramienta con la que se cuenta para responder al VIH/Sida es la prevención, sin embargo esta oportunidad no la tienen todos/as menos aún quienes tienen menos oportunidades sociales y económicas; mayormente solo quienes tienen acceso a la información y a medidas apropiadas de prevención, y cuentan con los medios para implementar esas medidas, serán capaces en el futuro de prevenir y/o protegerse contra la infección.

Como vemos, una de las realidades en las que se violan los derechos humanos es en la del $\mathrm{VIH} /$ sida. Uno de estos derechos es el de la información y educación sobre realidades que afectan la salud de las personas en todos sus aspectos. Los derechos tienen que ver también con la no discriminación e igualdad ante la ley, el derecho a la vida,

${ }^{12}$ Adolescente, hombre, 17 años, Quito. 
el derecho a la salud, el derecho a la libertad y seguridad de las personas, el derecho a la libertad de expresión, el derecho a liberarse de tratos y castigos inhumanos o degradantes, el derecho a la libertad de movimiento, el derechos al trabajo, entre otros.

La realidad del VIH-Sida en la actualidad es un problema del país, y es así como tenemos que responder a la epidemia. La sociedad civil, y el gobierno deben hacer una efectiva intervención en decisiones de carácter político, económico, y social, enfocados a reducir el crecimiento de la epidemia en el país, así como a dar una atención eficiente y efectiva a quienes requieren atención. El Ministerio de Economía debe tomar una actitud de atención a la epidemia y proveer de los recursos necesarios para mejorar los esfuerzos del Programa Nacional de Sida, Ministerio de Educación, Ministerio de Trabajo, pues la sensibilización para la educación y prevención juega un papel fundamental en aspectos sociales y de desarrollo económico.

\section{La construcción imaginaria del poder y el comporta- miento sexual desde la perspectiva de los/as adoles- centes y padres}

Para entender cómo se elabora la construcción imaginaria del poder en relación al comportamiento sexual, es necesario hacer referencia a afirmaciones conceptuales que refieren la característica de las relaciones de poder:

"Las relaciones de poder se caracterizan por la capacidad de unos para poder conducir las acciones de los otros, quienes a su vez tienen la capacidad de resistir, Hay efectos activos y reactivos. Los primeros son de orden de incitar, suscitar", producir" y obligar, los segundos de ser incitado, ser suscitado y ser obligado a producir"13.

${ }^{13}$ DÍAZ, Esther, La filosofía de Michel Foucault, pág. 102. 
Así también debe tenerse en claro que:

"La sexualidad es inminentemente práctica y su ejercicio tiene que ver con dos aspectos fundamentales: la relación con los otros y la búsqueda del placer. Los comportamientos en este sentido están determinados por la organización social y la cultura"14

Las normas, reglas, valores que están trazadas en la vida sexual de los individuos y colectividades y como estos se relacionan socialmente, están también matizadas a la vez de mitos, costumbres, tradiciones y ritos, como expresiones de una identidad cultural, que la que son parte subculturas, etnias, generaciones, etc., quienes son parte de los procesos de cambio que en su globalidad afectan el contexto cultural.

Las culturas son dialécticas, no son estáticas, los individuos y las sociedades también viven estos efectos, de tal manera que el comportamiento sexual y como se dinamizan las fuerzas de poder entre los grupos sociales también cambian. Este cambio obedece a que los factores culturales externos, así como los propios son diferentes, los lenguajes, las formas de relaciones, las representaciones también son afectadas en el transcurso de las generaciones.

"Nuestros viejos tenían como imagen a los Beatles. La forma de vestir era diferente, también en como vacilaban, la música. Nosotros tenemos otras formas de vestimos, cómo nos comportamos no es la misma de cómo lo hacían nuestros papás"15.

"En nuestro tiempo, nos comportamos de forma un poco diferente, las relaciones sexuales existían, es cierto pero quizá la forma era mas escondida, ahora los chicos

${ }^{14}$ TENORIO, Rodrigo. JARRÍN, María Soledad. La cultura sexual de los adolescentes, pag. 271.

${ }^{15}$ Adolescente hombre, 16 años, febrero, 1998. 
son mucho más atrevidos en ese sentido. Por ejemplo: Yo no le conversaba a mi papá sobre la última erección porque me pegaba, en cambio ahora mis hijos me dicen con quien estuvieron la noche anterior, aunque claro en su lenguaje a veces expresado en un guiño de ojo, una mirada que busca complicidad..."16.

Intentar entender el comportamiento sexual en las relaciones de poder, es importante considerar los factores sociales que se produce en un tiempo y en un espacio definido, las manifestaciones culturales que se viven en cada generación en la que se gestan, modifican, e insertan nuevos valores, y se los inserta dentro nuevas escalas, se conceptualizan y construyen nuevas representaciones que determinan el comportamiento individual y colectivo frente a situaciones determinadas.

Los valores, normas, conceptos, perspectivas de vida, la percepción de sí mismo y del otro se elabora en la relaciones sociales que se generan en el núcleo familiar, en los grupos, los medios de comunicación, las manifestaciones culturales, las nuevas formas de expresarse, lenguajes corporales y en del vestir.

"Las ideas y representaciones elaboradas, entendidas como la manera de ver, entender, interpretar o concebir una realidad, no son un producto casual ni se encuentran aisladas. Responden a un sistema basado en la realidad del mundo tal como es concebido e interpretado por cada grupo socio-cultural"17.

En el comportamiento sexual de los/las adolescentes, existen mitos, ritos, fantasías, que son parte de las relaciones que se desarrollan entre hombres y mujeres. Construyen una imagen sobre sí mismos, y la "del otro", es

\footnotetext{
${ }^{16}$ Padre de Familia, 45 años, octubre, 1998.

${ }^{17}$ YANEZ COSSIO, Consuelo, Representaciones y conceptos estructurales: un aporte al método, pág. 33.
} 
la representación que se elabora en la práctica de la atracción, la seducción y la conquista.

"Las chicas de ahora no son como en nuestro tiempo, no lo digo en el sentido de juzgarlas. Yo creo que expresan lo que son de la forma más natural, son otros tiempos. Si en mi tiempo me hubiese puesto las minis que ahora usa mi hija, en mi casa no me dejaban salir a la calle, en cambio, si mi hija se pone no me opongo porque es parte de la identidad de los/las jóvenes de ahora, la forma en como se comunican, y te aseguro que mi hija no es ninguna loca, es una chica tranquila por lo menos así la percibo yo"18.

En las actitudes y comportamientos de los jóvenes, hombres y mujeres existen códigos en el lenguaje, ritos de conquista, que forman parte de las relaciones de poder y comunicación que son manejadas por ellos y ellas. En la iniciación de los ritos de conquista, se manifiestan sentimientos, afectos, necesidades de ternura, necesidades de sentirse reconocidos y aceptados por el otro.

Así llegan al enamoramiento, y a otras necesidades como la de sentir la excitación, el placer y a vivir relaciones sexuales muchas de ellas desprotegidas.

"En mi grupo de amigos, hay algunos que se sienten más hombres, se creen gallazos cuando se pegan un polvo, y si la man es virgen, mejor"19.

"Cuando alguna chica llega a tener relaciones sexuales, es porque por lo general está enamorada, no es que sea víctima del chico, sino que lo hacen sabiendo lo que hacen, no es que no saben, sino que están super enamoradas y entregan todo, y punto"20.

En muchos contextos, el rito de la conquista por parte del hombre está influenciado por el valor del machis-

\footnotetext{
${ }^{18}$ Madre de familia, 35 años, octubre de 1998.

${ }^{19}$ Adolescente hombre, 15 años, octubre del 2004.

${ }^{20}$ Adolescente mujer, 17 años, octubre de 1998.
} 
mo que ha sido sostenido por el sistema del cual es parte, que además le presiona a probar que es capaz de conquistar, de "hacer que la loba caiga en sus manos". Mientras que para las chicas este rito lo viven de una forma diferente, para ellas es parte de una demostración de afecto.

Sin embargo, no siempre el machismo es el factor determinante que lleva a los varones a experimentar relaciones sexuales. También en ellos hay otro tipo de valores como la entrega, el afecto, el amor. Por otra parte actualmente muchas chicas son quienes seducen, ya no se puede decir que los hombres son los únicos seductores y quienes sugieren tener relaciones sexuales o quienes engañan solo por conseguir su objetivo "acostarse y sumar una más a su lista".

Actualmente también en muy frecuente escuchar en los/las adolescentes las vaciladas, que se refieren a los contactos sexuales ocasionales en pareja, estos encuentros ocurren en lugares como casas de amigos/as durante una fiesta, o puede suceder en otros lugares como una discoteca, etc., en si mismo el lugar es lo de menos. Luego de pasar juntos siguen como amigos o conocidos sin ningún compromiso en este tipo de contactos los/las las diferencian claramente de las relaciones más duraderas (amarre) en las que hay atracción, un compromiso amoroso, que es lo que anteriormente se conocía como enamorados.

"En mi curso hay chicas que se acuestan con chicos que solo conocen en una fiesta, a ellas no les da nada contar esas cosas, se creen super maduras"21.

Es muy frecuente escuchar "los tiempos cambian, las relaciones sexuales entre jóvenes hoy se ven de forma natural, es algo que tienen que pasar "22. La ausencia de programas sostenidos de educación sexual integral, rela-

\footnotetext{
${ }^{21}$ Adolescente 16 años, mujer, Quito, enero 2005.

${ }^{22}$ Adolescente 15 años, Quito enero del 2005.
} 
ciones sexuales desprotegidas, pero sobre todo que ellas no reconozcan su vulnerabilidad las ponen en alto riesgo de embarazos no deseados, de Infecciones de transmisión sexual como es el VIH/Sida.

Por parte de los padres, ven a la práctica de relaciones sexuales, como algo que está sucediendo pero prefieren pensar que esta realidad esta lejos de sus hijos. La mayor parte de padres desean que sus hijos/as lleguen a ser adultos con actitudes positivas, naturales y responsables frente al sexo y la intimidad.

Adentrarse en el comportamiento sexual de los/las adolescentes exige reconocer que las realidades contextuales de la cultural en la que se desenvuelven actualmente tiene un entorno diverso, variado y diferente del contexto socio-cultural en el que se desenvolvieron sus padres cuando tuvieron edades entre los 14 y 18 años.

\section{Mirada retrospectiva del VIH/Sida desde la "mismicidad" y "otredad"}

\section{Una mirada retrospectiva del VIH/Sida}

Según datos proporcionados por la OMS, " las primeras pruebas de infección por el virus del $\mathrm{VIH}$, datan de un suero almacenado en el África Central en 1.959"23. Sin embargo, es en la década de los años 70 que el VIH/SIDA, empieza a manifestarse como una nueva enfermedad, para entonces ya existían los primeros indicios de la existencia de síntomas aún cuando no se conocían las causas. En el 80 se diagnosticó oficialmente el virus, el comportamiento de este "nuevo enemigo" de los epidemiólogos, retó a la ciencia al desafío de " conocerlo y erradicarlo".

Los investigadores trataron de dar varias explicaciones al origen del VIH/Sida. El desconocimiento, llevó a que

\footnotetext{
${ }^{23}$ Boletín SIDA, MAP Internacional, vol 1, No 2, junio 992.
} 
a nivel de los científicos y, a partir de ellos con las elucubraciones que hacían alrededor de su "nuevo enemigo", se construyó un imaginario colectivo matizado por el terror, pánico, frente a todo lo que representaba el VIH/Sida.

Al imaginario colectivo, contribuyó, también la forma cómo se difundió la información respecto a la nueva epidemia. Las versiones sobre el origen se fueron sustentando en concepciones míticas, discriminativas; a las que de una manera u otra también se les dio una credibilidad, aun cuando no se llegaron a comprobar la veracidad de tales afirmaciones.

"Inicialmente la información a la que se tenía acceso apuntaba a afirmar que el SIDA tuvo su origen en el África, en vista de que un grupo de monos africanos, criados en cautiverio, sufrían la enfermedad causada por el virus de Inmudeficiencia Símica (VIS ), y estos transmitieron el virus al ser humano por contacto sexual"24.

Según esta versión, sobre el virus se había transferido al género humano, a través de relaciones sexuales de tribus africanas que practicaban ritos en los que las mujeres se untaban sangre de los monos en los órganos genitales. Otra versión sostenía que el virus del VIH fue producto de experimentos de armas biológicas "el SIDA fue creado en un laboratorio como un arma biológica durante la guerra de Vietnam"25.

De esta manera, la epidemia fue extendiéndose a nivel de todo el mundo, los casos diagnosticados no solo se encontraron el África, sino también en Estados Unidos, Europa, Asía, y pronto en América Latina. Entre los primeros casos de $\mathrm{VIH} /$ Sida estaban personas identificadas como homosexuales, trabajadoras sexuales y usuarios de drogas,

\footnotetext{
${ }^{24}$ Boletín SIDA. MAP Internacional, vol 1, No 2, junio1992.

${ }^{25}$ Idem.
} 
por eso se le calificó también como la enfermedad de los "promiscuos", descargándose un juicio de valor moral.

"La culpa del SIDA, la tiene la gente degenerada: homosexuales, prostitutas, drogadictos- porque es gente que no tiene moral, que no les importa nada en la vida, ni la familia, ni ellos mismos"26.

Frente a esta realidad, las personas que vivían con el VIH/Sida y sus familias, se enfrentaban con el abandono, la discriminación, el juicio colectivo, basado en creencias, mitos, la connotación del juicio sobre la vida sexual, moral, de las personas directamente afectadas, contribuía a la construcción colectiva del miedo alrededor de la epidemia.

Una mirada desde la "mismicidad"

Es importante conocer la percepción de la realidad del $\mathrm{VIH} /$ Sida, desde quienes lo viven directamente. La forma como la epidemia ha repercutido en la vida de las personas que viven directamente sus efectos, les permite que puedan tener una percepción propia y muy distinta respecto a la colectividad social, sobre el proceso de la epidemia desde sus inicios al momento actual.

"En el colegio vinieron a hacer unos exámenes y después vinieron con los resultados, a mí y otros chicos nos llamaron y nos dijeron que los exámenes habían salido positivos, en el colegio nadie más supo, solo nuestros papás, la rectora y el médico, pero después teníamos mucho miedo que nos sacaran del colegio, eso no pasó; pero Yo siempre tuve miedo que mis amigos se enteren, ahora tengo miedo que no me dejen entrar en la Universidad o que si no entro tenga que trabajar y también me pidan el examen de Elisa "27.

\footnotetext{
${ }^{26}$ Mujer 38 años. Quito, agosto, 1994.

${ }^{27}$ Adolescente 18 años, Guayaquil, septiembre del 2000.
} 
Para un adolescente que está viviendo cambios físicos, emocionales, afectivos, sociales etc., enfrentar la realidad de VIH/Sida resulta doblemente más difícil que a un adulto, hay un miedo que se manifiesta sobre todo en el ser juzgado por su conducta, miedo a que el juicio venga sobre todo desde su familia o amigos, miedo a que a su edad empiece a cerrársele puertas para seguir adelante con sus proyecciones como adolescente, estudiante, y/o ciudadano. Este miedo representa la percepción esotérica como refiere Julio Carvajal: "La perspectiva esotérica está referida a cómo un grupo piensa de si mismo y a cómo supone que otros piensan sobre él"28.

Desde la mismidad, las personas que enfrentan directamente la epidemia tienen miedo de las consecuencias que tiene el SIDA en la sociedad. Es interesante que muchos, asumen la responsabilidad de prevenir que "los otros" no enfrenten lo que "ellos" han tenido que enfrentar. El impacto que muchos han vivido al recibir la noticia del diagnóstico, el temor a que los demás se enteren, el temor a ser marginados, a la soledad, a sentirse abandonados, a perder el trabajo, etc., ha llevado a algunas personas que viven con el VIH/Sida demostrar que son aún útiles para sí mismos y para los "demás" para los "sanos", a demostrar que las personas no deben ser valoradas desde el Estado como sujetos económicamente productivas o no, sino desde su condición como seres humanos.

Una mirada desde la "otredad"

Para quienes ven el SIDA desde afuera, creen que se trata de una epidemia que es consecuencia de conductas y comportamientos errados, sobre todo relacionados

${ }^{28}$ CARVAJAL, Julio. Antropología y turismo en: Antropología, Patricio Guerrero (compilador), pág. 291. 
con la vida sexual y en segundo lugar el uso de jeringas infectadas, sin dejar de lado casos aislados relacionados con la negligencia médica. Sin embargo, en estos 25 años de presencia del VIH/Sida, la sociedad ha cambiando su actitud frente a las personas que viven con VIH/Sida, antes se consideraba que el SIDA era la enfermedad únicamente de los "promiscuos", hoy es para la mayor parte una enfermedad de transmisión que está ligada a conductas de comportamiento, y no de personas.

Las campañas de información eran dirigidas a una población masiva sin estudio de audiencias, la información estaba además cargada de alarma, y de prohibiciones. NO era la palabra que resaltaba en todos los medios de información, "No tenga relaciones sexuales sin conocer a su pareja. No sea infiel. No use jeringas infectadas". "Los índices de mayor incidencia del SIDA están entre el grupo de homosexuales", etc.

El gobierno tampoco tenía una política de información, adecuada, la información desplegada por los medios masivos estaba cargada de miedo y alarma. La manera cómo se difundieron las primeras noticias respecto al origen del SIDA, las formas de transmisión del VIH/Sida, también llevó a las sociedad a segregar, discriminar a las personas que eran diagnosticadas con el virus del $\mathrm{VIH}$, junto a la información desplegada a través de diferentes medios masivos, llevó a que la sociedad construyera sus propios imaginarios respecto a la transmisión del VIH/Sida.

Esta errada percepción respecto a la transmisión del $\mathrm{VIH} / \mathrm{Sida}$, contribuyó significativamente al miedo social y a la segregación, marginación, abandono que han tenido que vivir las personas que enfrentan directamente la epidemia hasta los momentos actuales.

Hoy el temor existe, quizá no manifestado con el mismo pánico que hace 25 años, cuando no se sabía casi nada respecto al VIH/Sida. Actualmente hay más informa- 
ción, pero a pesar de esto, los mismos medios de comunicación se encargan se mantener a los "otros" en la oscuridad, en el anonimato, cuando presentan una imagen sombrosa (distorsionada) de quien está hablando de su testimonio como persona que vive con el VIH/Sida. En este caso, el miedo se manifiesta desde la otredad y desde la mismidad, la sombras son una manifestación de que el VIH/Sida sigue tras lo oculto -lo oculto causa miedo- Desde la mismidad, el miedo está relacionado con la forma en cómo es manejada la noticia. Existe también el temor de que la noticia exagere la realidad, lo que generalmente ocurre con el sensacionalismo.

Respecto al uso del terror que hacen los medios de información, Pommier indica "existe una utilización mediática de esta enfermedad, que a me parece chocante, como mostrar personas a punto de morir de SIDA, por ejemplo con imágenes en televisión" 29 .

En la sociedad hay un conocimiento aún muy básico de las formas en cómo se transmite el SIDA, y más aún hay una fuerte desinformación, porque no siempre los mensajes llegan de forma clara y completa. Esta desinformación, así como también la manera cómo se transmite una información cuando está cargada de terror, genera miedo social. Muchas veces el temor también está asociado con el autocuestionamiento de la posibilidad de haberse infectado en alguna ocasión, sobre todo, cuando que se reconoce que se ha tenido conductas y comportamientos que le enfrenta a situaciones de riesgo.

"Una vez me acosté con una pelada que no sabía ni quién era... después de unas semanas me salieron unos granitos y un amigo me dijo que así era el Sida, pero después le preguntamos al doctor del colegio y el nos explicó, claro que no le dijimos porque estábamos ocultándole, solo

${ }^{29}$ GERAR, Pomier. El imaginario del SIDA en la postmodernidad, pág. 25. 
le dijimos que era para un deber, al principio creía que seguro esa pelada me había contagiado"30.

La percepción, las actitudes, los imaginarios que aún se sostienen y que continúan construyéndose alrededor el $\mathrm{VIH} /$ Sida, llevan a pensar que a pesar de que estamos a fines del milenio, todavía existe un miedo generalizado. Esto es una muestra más de que el problema no es solo la presencia de un virus, ni que la solución está en descubrir la vacuna contra el virus del SIDA.

Lo hasta aquí expuesto como una mirada desde la otredad, confirma que las campañas de información manejadas desde el Estado, los medios de comunicación masiva, etc., así como el fracaso de la ciencia en buscar la cura, han contribuido a que se genere miedo social, lo que agrava la falta de solidaridad, y rompe la alteridad. Además, el miedo es muy difícil de hacerlo desaparecer porque forma parte de los individuos y las sociedades, y lo usan como protección contra los "otros".

La presencia de mitos, dogmas, creencias causantes de la ceguera crónica que legitiman condiciones de injusticia, como el machismo, la discriminación, el individualismo, entre otros factores, son en realidad los que deben ser entendidos, y sobre los que deben plantearse los mecanismos para responder a la epidemia del VIH/Sida, y otras enfermedades infecciosas causadas por los factores ya mencionados.

Conocer la mirada desde la mismidad, y desde la otredad, nos demuestra, que el VIH/Sida tiene representaciones diferentes desde los dos espacios. El vivir con esta realidad, ha permitido entender que para unos, la presencia de enfermedades infectocontagiosas como la del VIH/Sida representa un problema humano, social, que responde a factores de pobreza, de falta de políticas que aseguren la

${ }^{30}$ Adolescente, hombre. Quito, junio 2004. 
vida de todas las personas, de responsabilidad frente a la vida desde la persona y la sociedad. Para otros el VIH/Sida es una epidemia resultado de lo "promiscuo", de lo incorrecto "comportamiento moral".

\section{Alternativas de prevención frente al VIH/Sida}

Las alternativas de educación y prevención de $\mathrm{VIH} / \mathrm{Sida}$ desde la perspectiva de los/las adolescentes son entendidas con una visión de respeto por sus derechos y deberes en decisión, participación en el planteamiento de propuestas, conceptualización, diseño, ejecución, seguimiento y evaluación de los programas en los que participan.

Consideran que para que los programas de educación y prevención frente al $\mathrm{VIH} /$ Sida tengan efectividad en reducir el avance de la epidemia, estos deben trabajarse de forma permanente a largo plazo y como parte de su formación escolar.

"No, no estoy de acuerdo con campañas ni con las charlas que se dan en los colegios porque no sirven para nada, los chicos van por perder clases, o por curiosidad, pero no toman nada en serio, deben ser programas o cursos, no sé... serios en los que nosotros seamos tomados en cuenta en como hacer estos programas" ${ }^{31}$.

Las campañas no tienen ningún efecto si las mismas no son parte de un programa integral en el que el eje fundamental es la implementación de un programa permanente de educación planteando realidades en las que los/las adolescentes se sientan identificados/as a nivel personal y colectivo con sus contextos socioculturales, generacionales, realidad barrial, realidad de grupo, realidad de género etc.

"A mí me gusta cuando por ejemplo se han tenido talleres en los que opinamos y no nos cuestionan por lo que

\footnotetext{
${ }^{31}$ Mujer adolescente, 16 años. Sto. Dgo. de los Colorados, diciembre del 2004.
} 
decimos, si nos equivocamos nos ayudan a reflexionar, nos aclaran ideas pero también nos respetan, así aprendemos y nos sentimos que toman en cuenta lo que sentimos y pensamos"32.

En los espacios de diálogo los/las adolescentes participantes expresan sus opiniones sobre alternativas de prevención, así como los obstáculos de carácter social, cultural, moral con los se confrontan cuando se hace un planteamiento real de sus mismas propuestas.

Para los varones, el preservativo es la alternativa más accesible y práctica, sin embargo, en la realidad reconocen que muy pocos (de 1 a 2 adolescentes de grupos de 25 a 30) $)^{33}$ lo usan de forma correcta y en cada relación sexual. Esto se debe a factores como temor a ser juzgados por los adultos, no les gusta usar porque la relación sexual no resulta igual. Para muchos el preservativo representa un símbolo de poder, algunos jóvenes llevan el condón en el bolsillo, en la billetera, para mostrarlo entre sus amigos, pero en realidad no lo usan siempre, o no saben usarlo correctamente. Las relaciones sexuales son improvisadas, por eso muchos se olvidan de usarlo.

Las mujeres, consideran que la chica que decide tener relaciones sexuales debe exigir al chico que use un preservativo. Sin embargo algunas chicas dicen que no lo dirían, porque el hacerlo les expone al juicio de su enamorado. De manera que aun cuando reconocen que deben exigir el uso del preservativo, aún se mantiene un prejuicio machista, la opinión del hombre está por encima de lo que ellas mismas puedan pensar. Para las jóvenes, es muy importante la imagen que los "otros" se forman de la mujer, sobre todo lo relacionado a su vida sexual.

"Yo creo que las chicas que están teniendo relaciones sexuales deben exigir a sus enamorados que lo use, pero lo

\footnotetext{
${ }^{32}$ Hombre adolescente, 17 años. Sto. Dgo. de los Colorados, diciembre del 2004.

${ }^{33}$ Taller con hombres adolescentes, Quito, julio del 2004.
} 
que pasa es que ellos piensan que les están exigiendo porque ellas ya han estado con otros pelados y van a pensar lo pero de ellas" 34 .

Hombres y mujeres consideran que la abstinencia es la alternativa más segura, para prevenir embarazos y enfermedades de transmisión sexual y VIH/Sida. Sin embargo, también piensan que es la más difícil de lograr. Esta alternativa fue sostenida, o propuesta sobre todo por las mujeres.

Las dificultades que enfrentan para lograr la abstinencia, están relacionadas en el caso de los jóvenes principalmente al machismo. En el caso de las mujeres, la mayor parte indican que hay presión por parte del chico y ellas tienen miedo a perderlo. Para hombres y mujeres creen que es posible; sin embargo reconocen que no es fácil porque cuando están frente a la seducción les resulta difícil resistir por razones de autoestima, de falta de claridad en que debe basarse una relación de amistad y enamoramiento, no saben como manejar la relación de intimidad; muchos/as reconocen la necesidad de afirmar una relación en valores de equidad y justicia pero que hace falta ser acompañados por adultos que sean referentes de apoyo en su desarrollo:, aclaran que no quieren controlados o aconsejados/as sino acompañados/as por un adulto de apoyo o lo que se conoce como referentes de apoyo.

Ellos/as consideran que:

- Los talleres deben ser participativos, que haya reflexión, propuestas cada chico o chica de acuerdo a la diversidad de realidades

- Es importante que los profesores que están apoyándolos/as sean sensibles a sus derechos de participación como adolescentes tomado en cuenta sus realidades.

\footnotetext{
${ }^{34}$ Mujer adolescente, 16 años. Santo Domingo, noviembre del 2004.
} 
- Se realicen acciones diversas considerando lo lúdico, los espacios de participación juvenil, estrategias de relaciones de grupos, cultura, etc.

- En los programas de educación deben respetarse sus valores, decisiones, sin imponer las ideas del adulto, o de otros/as jóvenes.

- El tema de sexualidad debe ser tratado con los padres para que ellos puedan ser un apoyo y no un obstáculo.

- Las autoridades y profesores de los colegios deben ser más comprensivos $\mathrm{y}$, abiertos y no ser un obstáculo en la educación de la sexualidad y prevención del VIH/Sida.

- El Ministerio de Educación debe obligar a través de una ley que en todos los colegios se trate el tema de sexualidad y prevención del $\mathrm{VIH} /$ Sida, para no tener que pedir de favor las horas de clase a los profesores.

\section{Violación de los derechos}

Los derechos humanos son y deben ser una garantía para todos/as, sin embargo cada día todos/as somos testigos de su incumplimiento, esta agresión con el ser humano es aún más evidente y grave con quienes viven realidades de mayor vulnerabilidad, como es la pobreza, la diferencia de género, la diferencia étnica, las personas que viven situaciones como es el VIH/Sida, etc; y en medio de estas segregaciones aún se dan particularidades; por ejemplo en el caso de los/as adolescentes y la realidad del VIH/Sida sea en términos de prevención y/o atención, entre algunos los que con mayor frecuencia se violan son:

- La ausencia de programas de cobertura nacional sobre educación para una sexualidad saludable y la prevención del VIH/Sida.

- La exigencia de la prueba de Elisa para matrícula escolar en secundaria. 
- La negación de matrícula escolar cuando hay un diagnóstico VIH reactivo a la prueba de Elisa.

- La violación a la confidencialidad cuando hay casos de adolescentes VIH positivos/as.

- La ausencia de programas de atención en salud para adolescentes.

La discriminación y el estigma se manifiestan en las relaciones más cercanas y en los espacios menos esperados, así se puede constatar casos de rechazo familiar, de amigos/as y compañeros/as de trabajo, estudio, etc. Se han conocido casos de violación muchos de ellos desconocidos públicamente por el miedo a ampliar aún más la noticia y que como consecuencia de esto el rechazo es aún más grave.

"Hace poco realizamos el examen de Elisa a los alumnos de 5to. año, porque la ley de educación no lo prohíbe, es más de alguna manera lo sugiere, hubo un alumno al que el examen le salió positivo. Yo le comenté al rector primero para saber que debemos hacer, él me dijo que vaya a la casa el chico, compruebe donde vive, después vimos que era mejor que no darle la matrícula y aconsejar a los padres que le lleve al un hospital para que sigan el caso" 35 .

Este tipo de control que adoptan en algunos establecimientos educativos no tienen los argumentos legales debidamente argumentados para realizar los exámenes de diagnóstico, como en el caso anterior hay tres tipos de violación de acuerdo a la Ley de prevención, atención, y control del VIH/Sida: primero el examen de Elisa no se puede exigir a nadie, segundo no hubo una pre-consejería previa al examen, y tercero se faltó a la confidencialidad. Además, es evidente que en los establecimientos educativos no pre-

${ }^{35}$ Médico de Colegio. Quito, Abril 2004. 
veen cómo actuar profesionalmente en caso de que uno de sus alumnos/as resultase con un diagnóstico de $\mathrm{VIH} / \mathrm{Sida}$ positivo.

Sabemos que existe una enorme brecha entre el ideal de proteger los derechos de las personas que viven con VIH/Sida y en este caso de adolescentes. Es fundamental una revisión actual de los documentos jurídicos, complementar las leyes que se vuelven inservibles sin un reglamento que las garantice, y las mismas sean difundidas ampliamente para que sean conocidas y adoptadas en un pleno ejercicio ciudadano.

Propuestas de educación sexual y prevención del VIH/Sida enfocadas a los/las adolescentes

Desde que el VIH/Sida se hizo evidente y más aún desde cuando el crecimiento entre poblaciones cada vez más jóvenes fue creciendo, organismos internacionales, OGNS y en menor grado el gobierno implementaron diversos programas de información, educación para la prevención de VIH/Sida en adolescentes. Las modalidades particularmente se enfocaron desde dos marcadas posiciones ambas muy radicales, en muchos casos hasta la actualidad mantienen sus absolutismos.

1. Una de ellas impulsada con un enfoque conservador y moralista, en el que la propuesta de la abstinencia es vista como única, se afirman concepciones como las de guardar la virginidad hasta el matrimonio para ser entregado al otro (esposo/a) como símbolo de pureza, con un marcado énfasis sobre todo en las jóvenes, y con una dicotomía entre lo bueno y lo malo, lo correcto e incorrecto, el pecado y la salvación. 
2. Otra que propone enfáticamente el preservativo, como una alternativa, práctica, garantizando además como uno de los derechos al pleno ejercicio de la sexualidad. Desde algunos organismos que plantean el condón entre los/las adolescentes como medida de prevención, afirman que ellos y ellas tienen derecho al placer y para vivirlo deben experimentarse y protegerse con el uso del condón.

Ambos planteamientos en su radicalismo absoluto se hacen la guerra mutuamente, pero lo más preocupante y quizá lo que ninguna de las dos propuestas reconoce es que ambas violan el legítimo derecho de los adolescentes a elegir, y a hacerlo en base al respeto por el contexto socio-cultural en el que crecieron, en respeto y decisión de valores humanos y no tanto moralistas que desean conservar u optar, en el respeto por sus valores, emociones, afectos y sentimientos.

Ambas propuestas quizá han considerado únicamente sus propias percepciones y posiciones respecto a la sexualidad y más aún lo hacen desde una visión adulto-céntrica.

Sin querer caer en los absolutismos y tomando en cuenta las opiniones, reflexiones y propuestas de los/las adolescentes es importante y urgente que en todo modelo de educación sexual sea este para la prevención del $\mathrm{VIH} / \mathrm{Sida}$ o el mismo permita responder a cualquier otra realidad que ponga en riesgo la integralidad del adolescente, debe considerarse:

- El rol de los/las adultos como facilitadores en el proceso que enfrentan los/las adolescentes.

- Que el adulto no debe imponer lo que piensa, menos hablar solo alternativas únicas sino presentar un abanico de posibilidades las mismas que es válido sean orientadoras para una vida sexual saludable con una perspectiva integral. 
- La capacidad de los/las adolescentes para opinar, reflexionar, y hacer propuestas con un pensamiento crítico frente a todo lo que viven.

- Que ellos y ellas puedan:

* Identificar y afirmar su identidad.

* Trabajar en el autoestima saludable.

* Reconocer su entorno.

Definir lo que desean vivir, sus proyecciones y cómo lograrlo.

- Decidir:

*ómo manejar sus relaciones.

Qué valores desean afirmarse y relacionarse con los/las otros.

Cuáles son sus derechos y deberes, identificar si los ejercen o no, y cómo hacerlo.

* Cómo manejar sus relaciones de intimidad sin que estas afecten su desarrollo como seres humanos.

*ómo manejar la represión e imposición de otros.

- Los programas de educación para una sexualidad saludable y la prevención del VIH/Sida deben tener una perspectiva positiva y no negativa o represiva. Una de las observaciones hecha por los/las adolescentes es cuando los programas incluyen aspectos o términos represores como por ejemplo el hablar de abstinencia, ellos/as la relacionan con lo prohibido. Mientras que si se habla de postergar las relaciones sexuales el término conlleva a los/las adolescentes a entenderlo como una propuesta realmente de prevención, de tomar alternativas viables desde sí mismos/as para responder con mayor seguridad y precaución ante la presión seducción, imposición, etc. de grupo. 
- Igualmente, en el caso de la propuesta del condón, la idea no debe ser planteada desde el adulto para los/las adolescentes, debe considerarse el aspecto socio-cultural, además partir desde lo individual a lo colectivo como parte de una propuesta educativa en la que se prioriza el respeto por la reflexión, el análisis de realidades diversas.

- La información y formación deben ir de la mano para que sus decisiones sean tomadas en libertad desde su propia interioridad y en coherencia con la diversidad de realidades. 